\title{
The Effects of Magnesium Sulfate with Lidocaine for Infraclavicular Brachial Plexus Block for Upper Extremity Surgeries
}

\author{
Siavash Beiranvand ${ }^{1}$ Arash Karimi ${ }^{1}$ Majid Haghighat Shoar ${ }^{1}$ Maryam Baghizadeh Baghdashti ${ }^{1}$ \\ ${ }^{1}$ Department of Anesthesiology, Faculty of Medicine, Lorestan \\ University of Medical Sciences, Khorramabad, Iran \\ Address for correspondence Majid Haghighat Shoar, Lorestan \\ University of Medical Sciences, Khorramabad, A81, Iran \\ (e-mail: md.haghighatshoar@gmail.com). \\ J Brachial Plex Peripher Nerve Inj 2020;15:e33-e39.
}

\begin{abstract}
Keywords

- magnesium sulfate

- anesthetic

- infraclavicular

- brachial plexus

- pain

- lidocaine

Background An addition of analgesic to anesthetic agents is likely to increase the effects of anesthesia and reduce associated adverse outcomes. Several adjuvants are studied in this regard. The aim of this study is to investigate the effects of adding a magnesium adjunct to lidocaine for the induction of infraclavicular block.

Methods Patients referred to Shohada Ashayer Hospital, Khorramabad, for wrist and hand surgery were enrolled in this study. The intervention/case group included patients who received $18 \mathrm{~mL}$ lidocaine $(2 \%)+2 \mathrm{~mL}$ magnesium sulfate $(50 \%), 10 \mathrm{~mL}$ normal saline; control group: $18 \mathrm{~mL}$ lidocaine $(2 \%)+12 \mathrm{~mL}$ of normal saline. After the induction of ultrasound-guided infraclavicular block, parameters such as duration of reach with respect to complete sensory and motor block, hemodynamic parameters (hypotension and bradycardia), and postoperative pain, using visual analogue scale criteria, were measured. The obtained data were analyzed using a Bayesian path analysis model.

Results A total of 30 patients were included in each group. In the case group, sensory and motor block was achieved for $12.136 \pm 4.96$ and $13 \pm 3.589$ minutes more than those in the control group. The duration of sedation and immobilization was $2.57 \pm 0.764$ minute and $4.66 \pm 0.909$ minutes lengthier in the case group. Regarding the hemodynamic parameters, blood pressure was $0.217 \pm 5.031$ and $1.59 \pm 5.14$ units lower in the case group, immediately following the block and the surgery. Similarly, heart rate was $0.776 \pm 4.548$ and $0.39 \pm 3.987$ units higher in the case group, after 30 minutes and 2 hours of the procedure. A decrease in the pain was seen at 8,10 , and 12 hours after the surgery, as compared with the control group. An addition of magnesium to lidocaine for infraclavicular block resulted in a significantly longer sedation and immobilization period and decreased postoperative pain at 12 hours. Conclusion Heart rate and blood pressure did not decrease significantly in the case group. It can be concluded that addition of magnesium sulfate to lidocaine can produce better anesthetic and analgesic outcomes with low-to-no adverse effects.
\end{abstract}

received

September 30, 2019

accepted

June 30,2020
DOI https://doi.org/

10.1055/s-0040-1715578. ISSN $1749-7221$. (c) 2020 Georg Thieme Verlag KG Stuttgart · New York
License terms

(c) (1) 


\section{Introduction}

Orthopedic procedures such as those related to hand, wrist, and forearm procedures, despite being minor surgical procedures, are associated with a great amount of postoperative pain. Infraclavicular neural network block is useful in causing prolonged and effective postoperative analgesia in these patients. ${ }^{1}$

Ultrasound-guided infraclavicular brachial plexus nerve block has been practiced recently, where different approaches such as transverse, posterior costoclavicular, medial, distal, and proximal approaches are commonly used. ${ }^{2}$ The distal approach is conventionally used; however, the proximal method is likely to be associated with the lessened use of anesthetic agents. ${ }^{3}$ Nonetheless, pneumothorax and neuraxial spread are some common complications associated with the ultrasound guide. ${ }^{4,5}$

Lidocaine is a local anesthetic rapid-acting agent that is used for the blockade of motor and sensory fibers for up to 1.5 hours. ${ }^{6}$ Several adjuncts have been investigated to elevate the analgesic response of lidocaine for infraclavicular block. ${ }^{7}$

The effect of magnesium was first recognized for the treatment of arrhythmia and preeclampsia, and its effect on anesthesia and analgesia has recently been recognized. ${ }^{8,9}$ Magnesium sulfate has also been used as an adjunct to anesthesia in recent years. It is also an effective analgesic agent for perioperative pain. ${ }^{10,11}$ Researches have also reported that the intraoperative use of magnesium is characterized by a reduced use of anesthetics and muscle relaxants. ${ }^{12}$ Furthermore, opioid use, postoperative nausea and vomiting, hypertension, and shivering have met a decreased trend with the use of magnesium sulfate. ${ }^{13,14}$

This study is designed to evaluate the effects of addition of magnesium sulfate to lidocaine for infraclavicular neural network block in pain control during and after hand, wrist, and forearm surgery in patients referred to Shohada Ashayer Hospital in 2018.

\section{Methods}

The aim of this study was to evaluate the effects of magnesium sulfate supplementation with lidocaine for infraclavicular nerve block for postoperative pain management following hand, wrist, and forearm surgery in patients referred to Shohada Nassir Hospital, Khorramabad between February 2018 and 2019. Patients undergoing the procedure were selected by a simple sampling method, where patients were randomly divided into two groups; group A included the patients receiving magnesium sulfate with $2 \%$ of lidocaine and group B included the patients administered saline with $2 \%$ lidocaine. Patients aged 18 to 85 years, ASA I-II class, having consent to participate in the study were included in the study. Patients with contraindication of brachial nerve block (allergy to local anesthesia, local infection at injection site, and coagulopathy), traumatic nerve injury of upper limb, history of opioid abuse, alcohol and drug abuse, recent chronic analgesic treatment, celiac and meningitis, allergic to lidocaine, peripheral neuropathy, neuromuscular disease, pregnancy and lactation, specific psychosis disorders, cognitive impairments, and those who disagreed to participate were excluded from the study. After receiving a written consent, detailed explanations of the study were provided to the patients. The patients were allotted a unique code which was only known to the nurse in-charge of the anesthesiology unit.

The infraclavicular neural network block was performed by the anesthesiologist. Noninvasive monitoring (blood pressure, heart rate) was performed and Ringer's solution was infused. All patients received premedication $0.5 \mathrm{mg} / \mathrm{kg}$ midazolam and $2.2 \mathrm{mg} / \mathrm{kg}$ fentanyl, prior to the block. Under the guidance of ultrasound (Ezono 3000, Germany), using a linear ultrasound probe, the infraclavicular neural network was identified and the in-plane method with SonoPlex needle $(22 \mathrm{G})$ was used to inject the following as per the group allocations: case group: $18 \mathrm{~mL}$ lidocaine $(2 \%)+2 \mathrm{~mL}$ magnesium sulfate $(50 \%), 10 \mathrm{~mL}$ normal saline; control group: $18 \mathrm{~mL}$ lidocaine $(2 \%)+12 \mathrm{~mL}$ of normal saline.

The patient's block was placed in a supine position, where the patient's arm was abducted to reduce the depth between the plexus and the skin. The cords of the brachial plexus are seen as hyperechoic circles bordered by axillary artery. A needle was inserted using the in-plane method, from the inferior of the ultrasound transducer, $1 \mathrm{~cm}$ into the skin. After reaching the artery, anesthetic agents were induced.

Following the block, the patients were evaluated for hemodynamic changes and block complications, such as pneumothorax, hypotension, bradycardia, and hematoma. The decline in sensory and motor activity was assessed after every 2 minutes, following the block, until complete sensory block was achieved. Furthermore, during the surgery, sensory and motor assessment was performed after every 5 minutes, during the first 30 minutes of the surgical procedure. Subsequently, motor and sensory activity was monitored after every 15 minutes until the end of the surgery. In any case, where anesthesia failure was seen, 30 minutes after the bock, it was marked as the infraclavicular block failure. The magnitude of the motor block was measured with Bromage scores of 16:1=complete leg movement, 2 =partial movement, $3=$ relative movement, and $4=$ complete immobility.

Sensory block was measured by a pinprick test: $0=$ no sensation, $1=$ sensory loss, and $2=$ no sensory change. The duration of the sensory block is the period between the end of local anesthetic administration and normal sensory return. The duration of the locomotor block is the period between the end of local anesthetic administration and complete motor function reversal. The patient's blood pressure and heart rate were recorded before the block, 30 minutes after the end of the injection, at the end of surgery, and 2 hours after the surgery. If the blood pressure dropped below $20 \%$ of the baseline blood pressure, $5 \mathrm{mg}$ of ephedrine was injected. When the heart rate decreased below 50/minute, $0.5 \mathrm{mg}$ of atropine was injected. Postoperative pain was measured at 2, 4, 6, 8, 10, and 12 hours using the visual analogue scale criterion where 0 indicated no pain and 10 indicated worst pain imaginable. The pain was evaluated based on the type of the surgery performed and patients were educated accordingly regarding the perception of the pain. Side effects such as nausea, vomiting, bradycardia, hypotension, and itching at 4,8 , and 12 hours after surgery 
were also evaluated. The duration of the sensory block was the primary finding, whereas the duration of the motor block, onset of sensory and motor block, total opioid use, and postoperative pain score were secondary outcomes of the study. The obtained data were recorded in the evaluation form and were assessed using SPSS V. 21.

To investigate the effect of intervention (group A: lidocaine with magnesium sulfate; group B: saline with lidocaine) on the dependent variables in the neural network block subgroup (duration of anesthesia, onset anesthesia time, and onset immobility time), biological factors (blood pressure and heart rate), and pain at different times, a Bayesian path analysis model was used that could help us determine the significant correlation between the dependent variables in each subgroup. Since the correlation between the dependent variables is significant, concurrent statistical inferences were required, to determine the effects of the intervention on the dependent factors, for which route analysis was exploited. In Bayesian inference, the validity intervals, instead of $p$-value, are used to examine the significance of the effect of the intervention variable on the dependent variables. If the interval of validity is zero, the intervention was known to have no significant effect.

\section{Results}

The results of the study regarding the effects of intervention on dependent variables in the neural network block subgroup using Bayesian path analysis are shown below.

\section{Determination and Comparison of Sensory Block Duration in the Two Study Groups}

According to the obtained validity interval, it can be concluded that the intervention had a significant effect on the duration of anesthesia, as the duration of anesthesia for the target group patients was approximately $12.13 \pm 4.96$ minutes longer than the control group. In addition, variables such as age, gender, and body mass index (BMI) have significant effects on the duration of anesthesia (-Table $\mathbf{1}$ ).

\section{Determination and Comparison of Motor Block Duration in the Two Study Groups}

According to the obtained interval of validity, it can be deduced that the intervention had a significant effect on the duration of

Table 1 Bayesian path analysis output to investigate the effect of intervention, age, gender, and BMI on anesthesia duration

\begin{tabular}{|l|l|l|l|l|}
\hline Variable & Estimate & SE & Lower Cl & Upper Cl \\
\hline $\begin{array}{l}\text { Group } \\
\text { (ref = control) }\end{array}$ & 12.136 & 4.96 & 2.409 & 21.979 \\
\hline Age & 0.529 & 0.138 & 0.255 & 0.799 \\
\hline $\begin{array}{l}\text { Sex } \\
\text { (ref = male) }\end{array}$ & 12.49 & 4.839 & 3.202 & 22.112 \\
\hline BMl & 0.132 & 0.019 & 0.096 & 0.17 \\
\hline
\end{tabular}

Abbreviations: BMI, body mass index; $\mathrm{Cl}$, confidence interval; $\mathrm{SE}$, standard error.
Table 2 Bayesian path analysis output to investigate the effect of intervention, age, gender, and BMI on immobilization duration

\begin{tabular}{|l|l|l|l|l|}
\hline Variable & Estimate & SE & Lower Cl & Upper CI \\
\hline $\begin{array}{l}\text { Group } \\
\text { (ref = control) }\end{array}$ & 13.14 & 3.589 & 6.117 & 20.092 \\
\hline Age & 0.446 & 0.095 & 0.26 & 0.635 \\
\hline $\begin{array}{l}\text { Sex } \\
\text { (ref = male) }\end{array}$ & 9.258 & 3.484 & 2.02 & 15.699 \\
\hline BMl & 0.105 & 0.013 & 0.08 & 0.132 \\
\hline
\end{tabular}

Abbreviations: $\mathrm{BMI}$, body mass index; $\mathrm{Cl}$, confidence interval; $\mathrm{SE}$, standard error.

immobility, as the duration of anesthesia for the target group patients was approximately $13.14 \pm 3.589$ minutes longer than the control group. In addition, variables such as age, gender, and BMI have significant effects on the duration of immobility (-Table 2).

\section{Determination and Comparison of Time to Anesthesia in the Two Study Groups}

The mean time to anesthetize for the case group was approximately $2.57 \pm 0.764$ minutes longer than the control group. Considering the validity interval, it can be concluded that the intervention had a significant effect on the time to anesthetize. In addition, age and BMI had a significant effect, as well. However, no such difference was reported in terms of gender.

\section{Determination and Comparison of the Onset Time of Immobility in the Two Study Groups}

The median time to onset of immobilization in the case group was approximately $4.66 \pm 0.909$ minutes, which was lengthier than the control group. Furthermore, the variables such as age, gender, and BMI also had a significant effect on the onset time of immobility (- Table 3 and - Fig. 1 ).

\section{Determination and Comparison of Mean Blood} Pressure before Nerve Block in the Two Study Groups The mean blood pressure before neural block in the case group was estimated to be $3.1 \pm 4.941$ times higher than the control group. However, the difference did not show any statistical significance. Additionally, there was no significant difference

Table 3 Bayesian path analysis output to investigate the effect of intervention variables, age, gender, and BMI on the immobility onset time

\begin{tabular}{|l|l|l|l|l|}
\hline Variable & Estimate & SE & Lower Cl & Upper Cl \\
\hline $\begin{array}{l}\text { Group } \\
\text { (ref = control) }\end{array}$ & 4.66 & 0.909 & 2.86 & 6.442 \\
\hline Age & 0.118 & 0.022 & 0.074 & 0.161 \\
\hline $\begin{array}{l}\text { Sex } \\
\text { (ref = male) }\end{array}$ & 1.897 & 0.886 & 0.117 & 3.626 \\
\hline BMl & 0.016 & 0.003 & 0.01 & 0.022 \\
\hline
\end{tabular}

Abbreviations: BMI, body mass index; $\mathrm{Cl}$, confidence interval; $\mathrm{SE}$, standard error. 


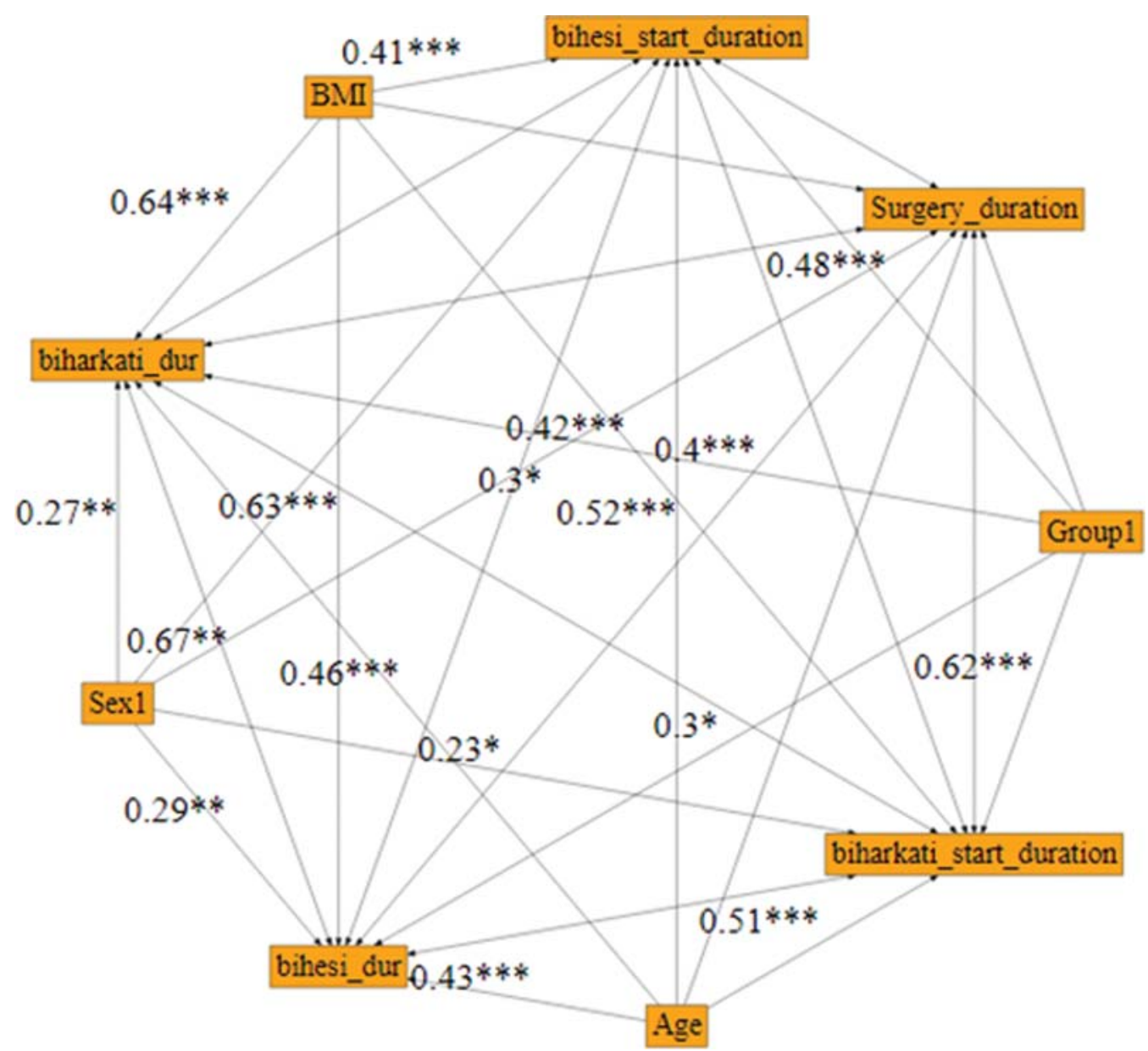

Fig. 1 Investigation of the effect of intervention on the dependent variables in the subgroup of biological agents at different times using Bayesian path analysis.

in the mean blood pressure in terms of gender; however, the effects of age and BMI on blood pressure were significant.

\section{Determination and Comparison of Mean Blood Pressure after Nerve Block in the Two Study Groups} The mean blood pressure after the nerve block for the patients in the case group was estimated to be approximately $0.21 \pm 5.031$ units lower than the control group, which was not statistically significant . In addition, there was no significant difference in mean blood pressure among gender groups. Nonetheless, the effect of age and BMI on blood pressure was significant.

\section{Determination and Comparison of Mean Blood Pressure after Surgery in the Two Study Groups} The mean blood pressure after surgery for the case group was estimated to be approximately $1.59 \pm 5.14$ units lesser than the control group. Statistically, there were no significant differences in this variable. But the effect of age, gender, and BMI on blood pressure was significant.

\section{Determination and Comparison of Mean Heart Rate before Neural Block in the Two Study Groups}

The mean heart rate before the nerve block for the patients in the case group was estimated to be approximately
$3.58 \pm 4.44$ units lesser than the control group. The association was not found to be statistically significant. Also, gender had no significant effect on the heart rate. But the effect of age and BMI on the heart rate was significant.

\section{Determination and Comparison of Mean Heart Rate after Surgery in the Two Study Groups}

The mean heart rate after the surgery for the patients in the case group was approximately $1.02 \pm 3.98$ units lower than the control group. Considering the obtained validity interval, it can be deduced that the mean heart rate after the surgery did not differ significantly between the case and control groups. Also, gender had no significant effect on the mean heart rate after surgery. But the effect of age and BMI on heart rate was significant.

\section{Determination and Comparison of Mean Heart Rate $\mathbf{3 0}$ minutes after Surgery in the Two Study Groups}

The mean heart rate 30 minutes after surgery for the patients in the case group was approximately $0.776 \pm 4.58$ units higher than the control group. According to the obtained validity interval, it can be deduced that this difference in heart rate between the case and control groups was not statistically significant. But the effect of age, gender, and BMI on heart rate was significant. 


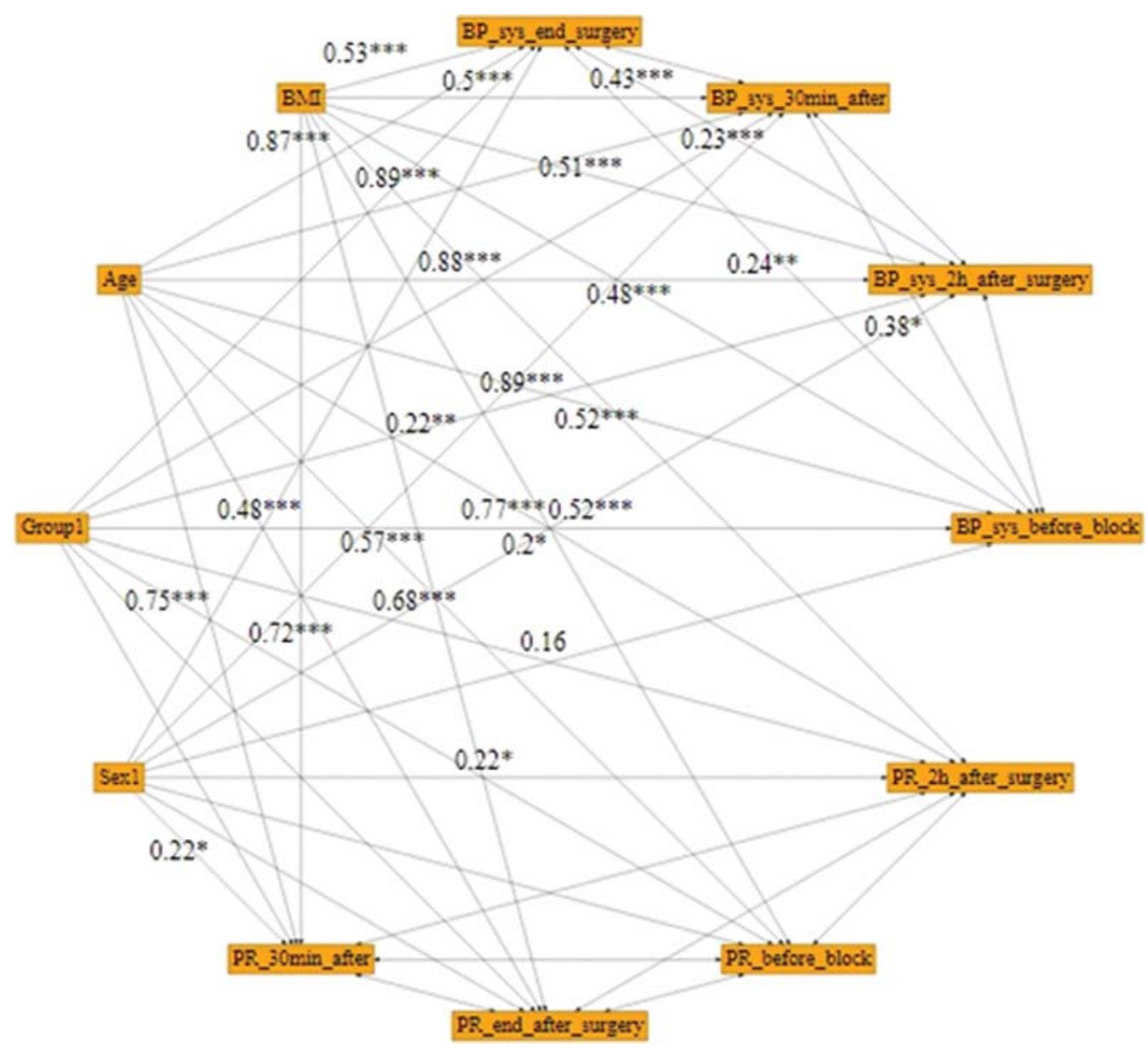

Fig. 2 Evaluation of the effect of intervention on pain at different times using Bayesian analysis.

\section{Determination and Comparison of Mean Heart Rate $\mathbf{2}$ hours after Surgery in the Two Study Groups}

The mean heart rate 2 hours after surgery was approximately $0.39 \pm 3.98$ more in the case group than in the control group. According to the obtained validity interval, it can be deduced that this difference in heart rate between the two groups is not statistically significant. But the effect of age, gender, and BMI on the heart rate 2 hours after the surgery was significant (-Fig. 2).

\section{Determination and Comparison of Pain 2 hours after Surgery in the Two Study Groups}

The mean pain, following 2 hours of the surgery, in the case group was approximately $0.598 \pm 0.507$ more than in the control group. Based on the obtained credit gap, it can be deduced that this difference is not statistically significant. Also, the age, gender, and BMI had no significant effect.

\section{Determination and Comparison of Pain 4 Hours after Surgery in the Two Study Groups}

The mean pain, following 4 hours of the surgery, was approximately $0.69 \pm 0.64$ more in the case group than in the control group. Based on the obtained credit gap, it can be deduced that this difference is not statistically significant. Also, gender had no significant effect on pain at 4 hours after surgery. But the effect of age and BMI on pain was significant.

\section{Determination and Comparison of Pain 6 Hours after Surgery in the Two Study Groups}

The mean pain 6 hours after surgery was approximately $0.12 \pm 0.765$ more in the case group than in the control group. Based on the obtained credit gap, it can be deduced that this difference is not statistically significant. Also, gender had no significant effect on pain at 6 hours after surgery. But the effect of age and BMI on pain was significant at this time.

\section{Determination and Comparison of Pain Rate 8 Hours after Surgery in the Two Study Groups}

The mean pain 8 hours after surgery was approximately $0.64 \pm 0.703$ units lower in the case group than in the control group. Based on the obtained credit gap, it can be deduced that this difference is not statistically significant. Also, gender had no significant effect on pain at 8 hours after surgery. But the effect of age and BMI on pain was significant at this time.

\section{Determination and Comparison of Pain Rate 10 Hours after Surgery in the Two Study Groups}

The mean pain 10 hours after surgery was approximately $0.61 \pm 0.46$ units less in the case group than in the control group. Based on the obtained credit gap, it can be deduced that this difference is not statistically significant. Also age had no significant effect on pain at 10 hours after surgery. But the effect of gender and BMI on pain was significant at this time. 


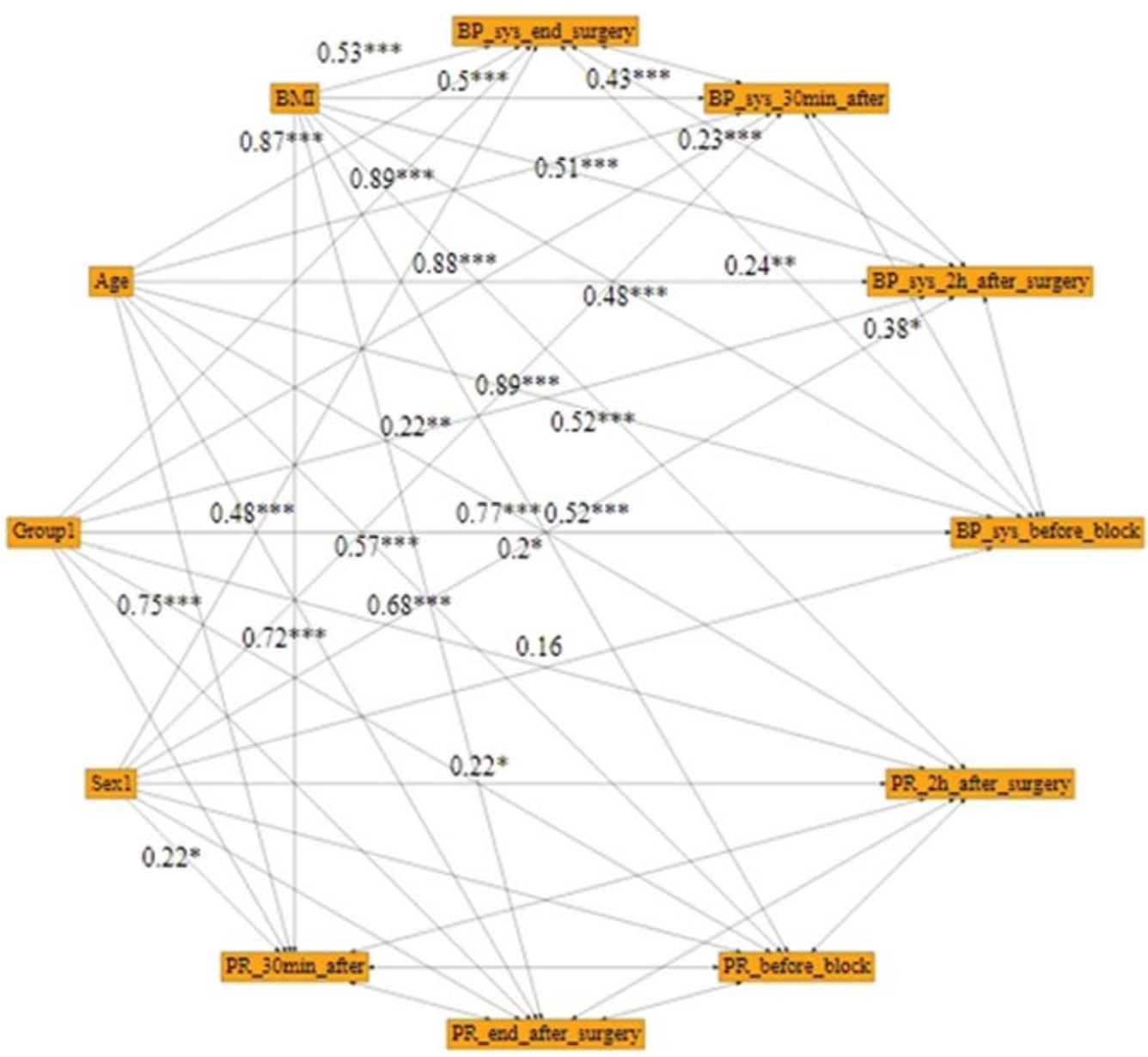

Fig. 3 Path analysis for pain-dependent variables at different times.

\section{Determination and Comparison of Pain Rate 12 Hours after Surgery in the Two Study Groups}

The mean pain 12 hours after surgery in the case group was approximately $0.88 \pm 0.382$ units lower than in the control group. Therefore, given the validity gap, it can be deduced that this difference is statistically significant. But age, gender, and BMI had no significant effect on pain at 12 hours after surgery (-Fig. 3 ).

\section{Discussion}

Studies have shown that addition of adjunct magnesium to lidocaine for intravenous regional anesthesia is associated with early onset of sensory block, increased duration of the anesthesia, and low to no side effects. ${ }^{15,16}$ In a controlled randomized trial, Haghighi et $\mathrm{al}^{17}$ found, in 30 patients administered magnesium along with lidocaine for axillary nerve block using the transarterial method, the duration of motor and sensory block to be significantly prolonged ${ }^{18,19}$ and invariant with only the lidocaine group. ${ }^{17}$ Furthermore, addition of a magnesium adjunct with lidocaine for Bier's block is also reported to decrease chronic limb pain and a number of failed treatments. ${ }^{20}$ Our study also reports that at 12 hours following the surgery, the intervention group (magnesium + lidocaine) had reduced incidence of postoperative pain.
Shoeibi et $\mathrm{al}^{21}$ presented in their study that the use of $10 \%$ magnesium sulfate is associated with a significant increase in the duration of spinal anesthesia in patients undergoing cesarean section surgery. ${ }^{22}$ In a comparative study, Mirkheshti et $\mathrm{al}^{23}$ reported that the addition of magnesium to lidocaine for upper extremity surgeries is associated with the increased onset of sensory and motor block and increased block length as compared with the usage of paracetamol with lidocaine.

In a study by Turan et $a{ }^{24}$ in patients undergoing hand surgery under regional anesthesia, addition of $15 \%$ magnesium sulfate to lidocaine significantly decreased postoperative pain at $15,20,30,40$, and 50 minutes along with a reduced need of diclofenac. Nonetheless, in our study, addition of $50 \%$ magnesium sulfate to lidocaine led to a decrease in pain at 2, 6, 8, 10, and 12 hours after surgery. However, this outcome was statistically significant only at 12 hours after surgery. ${ }^{25,26}$ Differences in the methods of statistical analysis can be one of the possible causes of the variations in the outcomes.

Our study also revealed that magnesium with lidocaine is not associated with significant unstable changes in hemodynamic parameters such as blood pressure and heart rate. Similar outcomes have been reported by some recent studies conducted for axillary brachial plexus block ${ }^{27}$ and laparotomy surgery. ${ }^{28}$ 


\section{Conclusion}

Magnesium sulfate with lidocaine is associated with increased anesthetic and analgesic efficiency with reduced postoperative adverse events. Comparison of various other adjuncts with greater sample sizes can give better inferences.

Note

All relevant data and materials are provided with in the manuscript.

\section{Authors' Contributions}

S. B. conceptualized and designed the study, drafted the initial manuscript, and reviewed and revised the manuscript. M. H. S. designed the data collection instruments, collected data, performed the initial analyses, and reviewed and revised the manuscript. A. K. and M. B. B. coordinated and supervised the data collection and critically reviewed the manuscript for important intellectual content. All authors approved the final manuscript as submitted and agree to be accountable for all aspects of the work.

\section{Funding}

None.

\section{Conflict of interest}

None declared.

\section{References}

1 Bonica J, Loeser J, Chapmann C, Fordyce W. The Management of Pain. 2nd ed. Philadelphia, PA: Lea \& Febiger; 1990

2 Yadav RK, Sah BP, Kumar P, Singh SN. Effectiveness of addition of neostigmine or dexamethasone to local anaesthetic in providing perioperative analgesia for brachial plexus block: a prospective, randomized, double blinded, controlled study. Kathmandu Univ Med J (KUMJ) 2008;6(23):302-309

3 Hsu AC, Tai YT, Lin KH, et al. Infraclavicular brachial plexus block in adults: a comprehensive review based on a unified nomenclature system. J Anesth 2019;33(03):463-477

4 Bhoi D, Narasimhan P, Nethaji R, Talawar P. Ultrasound-guided midpoint transverse process to pleura block in breast cancer surgery: a case report. A A Pract 2019;12(03):73-76

5 Kohli S, Kaur M, Sahoo S, Vajifdar H, Kohli P. Brachial plexus block: comparison of two different doses of clonidine added to bupivacaine. J Anaesthesiol Clin Pharmacol 2013;29(04):491-495

6 Ghadirian S, Vesal N. Brachial plexus block using lidocaine/ epinephrine or lidocaine/xylazine in fat-tailed sheep. Vet Res Forum 2013;4(03):161-167

7 Yaghoobi S, Shahamat H, Alizadeh A, Khezri MB. Comparing postoperative analgesic effect of dexmedetomidine or dexamethasone added to lidocaine through infraclavicular block in forearm surgery. Clin J Pain 2019;35(09):766-771

8 Telci L, Esen F, Akcora D, Erden T, Canbolat AT, Akpir K. Evaluation of effects of magnesium sulphate in reducing intraoperative anaesthetic requirements. Br J Anaesth 2002;89(04):594-598

9 Woolf CJ, Thompson SW. The induction and maintenance of central sensitization is dependent on N-methyl-D-aspartic acid receptor activation; implications for the treatment of post-injury pain hypersensitivity states. Pain 1991;44(03):293-299
10 Ryu J-H, Kang M-H, Park K-S, Do S-H. Effects of magnesium sulphate on intraoperative anaesthetic requirements and postoperative analgesia in gynaecology patients receiving total intravenous anaesthesia. Br J Anaesth 2008;100(03):397-403

11 Bazin J, Massoni C, Groslier D, Fenies V, Bittar M, Schoeffler P. Brachial plexus block: effect of the addition of sufentanil to local anesthetic mixture on postoperative analgesia duration. Ann $\mathrm{Fr}$ Anesth Reanim 1997;16(01):9-13

12 Shiga T, Wajima Z, Inoue T, Ogawa R. Magnesium prophylaxis for arrhythmias after cardiac surgery: a meta-analysis of randomized controlled trials. Am J Med 2004;117(05):325-333

13 Do S-H. Magnesium: a versatile drug for anesthesiologists. Korean J Anesthesiol 2013;65(01):4-8

14 Jarbo K, Batra YK, Panda NB. Brachial plexus block with midazolam and bupivacaine improves analgesia. Can J Anaesth 2005; 52(08):822-826

15 Bansal P, Baduni N, Bhalla J, Mahawar B. A comparative evaluation of magnesium sulphate and nitroglycerine as potential adjuncts to lidocaine in intravenous regional anaesthesia. Int J Crit Illn Inj Sci 2015;5(01):27-31

16 di Benedetto P, Bertini L, Casati A, Borghi B, Albertin A, Fanelli G. A new posterior approach to the sciatic nerve block: a prospective, randomized comparison with the classic posterior approach. Anesth Analg 2001;93(04):1040-1044

17 Haghighi M, Soleymanha M, Sedighinejad A, et al. The effect of magnesium sulfate on motor and sensory axillary plexus blockade. Anesth Pain Med 2015;5(01):e21943

18 Arcioni R, Palmisani S, Della Rocca M, et al. Lateral popliteal sciatic nerve block: a single injection targeting the tibial branch of the sciatic nerve is as effective as a double-injection technique. Acta Anaesthesiol Scand 2007;51(01):115-121

19 Li M, Jin S, Zhao X, et al. Does magnesium sulfate as an adjuvant of local anesthetics facilitate better effect of perineural nerve blocks?: a meta-analysis of randomized controlled trials Clin J Pain 2016;32(12):1053-1061

20 Place HM, Enzenauer RJ, Muff BJ, Ziporin PJ, Brown CW. Hypomagnesemia in postoperative spine fusion patients. Spine 1996; 21(19):2268-2272

21 Shoeibi G, Sadegi M, Firozian A, Tabassomi F. The additional effect of magnesium sulfate to lidocaine in spinal anesthesia for cesarean section. Int J Pharmacol 2007;3(05):425-427

22 Storm W, Zimmerman JJ. Magnesium deficiency and cardiogenic shock after cardiopulmonary bypass. Ann Thorac Surg 1997;64 (02):572-577

23 Mirkheshti A, Aryani MR, Shojaei P, Dabbagh A. The effect of adding magnesium sulfate to lidocaine compared with paracetamol in prevention of acute pain in hand surgery patients under intravenous regional anesthesia (IVRA). Int J Prev Med 2012;3(09):616-621

24 Turan A, Memiş D, Karamanlioğlu B, Güler T, Pamukçu Z. Intravenous regional anesthesia using lidocaine and magnesium. Anesth Analg 2005;100(04):1189-1192

25 Vahabi S, Rafieian Y, Abbas Zadeh A. The effects of intraoperative esmolol infusion on the postoperative pain and hemodynamic stability after rhinoplasty. J Invest Surg 2018;31(02):82-88

26 Beiranvand S, Vahabi S. Effect of local ropivacaine on hemodynamic responses in craniotomy patients. J Invest Surg 2018;31(06):464-468

27 Shahtaheri Y, Kamali A, Rad MT, Yazdi B. Comparison of hemodynamic changes of magnesium sulfate and dexmedetomidine for an axillary brachial plexus block. J Family Med Prim Care 2019;8 (07):2223-2228

28 Aghamohammadi D, Farzin H, Khanbabayi Gol M, Fooladi S. The effects of intravenous magnesium sulfate on hemodynamic status and pain control in patients after laparotomy surgery: a double blind clinical trial. J Anesthesiol Pain 2018;9(03):66-73 